\title{
Investigation of risk factors for prostate cancer patients with bone metastasis based on clinical data
}

\author{
YOSHIAKI YAMADA $^{1}$, KATSUYA NARUSE ${ }^{1}$, KOGENTA NAKAMURA ${ }^{1}$, TOMOHIRO TAKI ${ }^{1}$, \\ MOTOI TOBIUME ${ }^{1}$, KENJI ZENNAMI ${ }^{1}$, GENYA NISHIKAWA ${ }^{1}$, YOUKO ITOH ${ }^{1}$, \\ YOSHITAKA MURAMATSU ${ }^{1}$, HIROSHI NANAURA ${ }^{3}$, MIHO NISHIMURA ${ }^{2}$, \\ KAZUKO TAKII ${ }^{2}$, ADNAN ODHAFA KH. ADHAM ${ }^{4}$ and NOBUAKI HONDA ${ }^{1}$ \\ ${ }^{1}$ Department of Urology, Aichi Medical University School of Medicine; ${ }^{2}$ Division of Nursing, \\ Aichi Medical University Hospital, Aichi; ${ }^{3}$ Division of Urology, National Health Insurance Sakashita Hospital, \\ Gifu, Japan; ${ }^{4}$ Division of Urology, Basrah General Hospital, Basrah, Iraq
}

Received March 23, 2010; Accepted May 11, 2010

DOI: 10.3892/etm_00000099

\begin{abstract}
It has not yet been determined whether certain types of prostate cancer with bone metastasis (M1b PC) are associated with a poor outcome. The present study retrospectively assessed the potential significance of various clinical data in predicting the outcome of M1b PC. The subjects were 104 patients who attended our hospital and received a diagnosis of M1b PC between January 1998 and December 2006. The age of the subjects ranged from 51 to 91 years (median 74). The observation period ranged from 4 to 122 months (median 43). The parameters investigated were $\mathrm{T}$ classification, $\mathrm{N}$ classification, Gleason score (GS), pre-treatment prostate-specific antigen (PSA) level, extent of disease (EOD) grade, alkaline phosphatase (ALP), lactate dehydrogenase (LDH), calcium and hemoglobin $(\mathrm{Hb})$ levels and platelet count. The 5-year cause-specific survival rate was $56.6 \%$ and the 10 -year causespecific survival rate was $34.9 \%$. Log-rank test and Cox univariate analysis identified the following factors with statistically significant differences: pre-treatment PSA level $\geq 192$, N1, GS $\geq 8$, EOD grade 3+4, high LDH, high ALP and low $\mathrm{Hb}$. Multivariate Cox proportional hazard analysis identified the factors $G S \geq 8$ and high LDH with significant differences. The hazard ratio was 4.967 and 2.728 , respectively, and the probability value $(\mathrm{P})$ was 0.029 and 0.004 , respectively. When the subjects with GS $\geq 8$ and high $\mathrm{LDH}$ were classified as the high-risk group, the 5-year cause-specific survival rate was $24.6 \%$. The outcome was significantly poorer in this group
\end{abstract}

Correspondence to: Dr Yoshiaki Yamada, Department of Urology, Aichi Medical University School of Medicine, Nagakute, Aichi 480-1195, Japan

E-mail: yy1124@aichi-med-u.ac.jp

Key words: prostate cancer, bone metastasis, prognostic factor, Gleason score, lactate dehydrogenase
$(\mathrm{P}<0.0001)$ than in the other group, which had a 5-year causespecific survival rate of $67.7 \%$. The present study showed that patients with M1b PC with GS $\geq 8$ and high LDH have a very poor outcome and thus should be treated as a high-risk group requiring close follow-up.

\section{Introduction}

In the US, the incidence of prostate cancer (PC) ranks first among men, while the mortality from PC ranks second after lung cancer. In Europe, approximately 260,000 individuals are diagnosed with PC every year (1), and PC accounts for $9 \%$ of cancer-related deaths among men (2). The frequency of PC varies from country to country; it has been reported to be lowest in the Far East, particularly in mainland China and Japan (3). In Japan, however, the frequency in 2015 is expected to increase to 4.6 times that in 1985 (4), and a recent study revealed that $\mathrm{PC}$ screening would reduce mortality from PC by $20 \%$ (5). PC will thus become an increasingly important disease in men. Patients with $\mathrm{PC}$ have only vague symptoms in the early phase of the disease; it is not rare for patients who present with a chief complaint of bone pain or neurological symptoms to have PC with bone metastases at the time of diagnosis (6). Most PC is androgen-dependent. Patients with metastatic PC are rarely cured and most of them are treated by endocrine therapy. In the majority of such patients, however, resistance to endocrine therapy develops within several years. Endocrine resistance is considered to be acquired through abnormalities in the androgen receptor as well as a mechanism independent of the androgen receptor (7). At present, however, the characteristics of patients in whom endocrine-therapy resistance is likely to develop have not been clarified, and no effective therapy has been established for endocrine therapy-resistant PC.

The present study retrospectively assessed the potential significance of various clinical data (serum biochemical data and pathological findings) in predicting the outcome of prostate cancer with bone metastasis (M1b PC) after endocrine therapy. 
Table I. Patient characteristics.

\begin{tabular}{|c|c|}
\hline Patient, n & 104 \\
\hline \multicolumn{2}{|l|}{ Age (years) } \\
\hline Range & $54-91$ \\
\hline Average $( \pm \mathrm{SD})$ & $74.2 \pm 7.4$ \\
\hline Median & 74 \\
\hline Serum PSA (ng/ml) & $10-100,060.0$ \\
\hline Average $( \pm \mathrm{SD})$ & $920.1 \pm 1759.3$ \\
\hline Median & 268.7 \\
\hline Follow-up period (months) & $4-122$ \\
\hline Average $( \pm \mathrm{SD})$ & $46.9 \pm 29.1$ \\
\hline Median & 43 \\
\hline \multicolumn{2}{|l|}{ Treatment } \\
\hline MAB & $93(89.4 \%)$ \\
\hline LH-RH agonist monotherapy & $2(1.9 \%)$ \\
\hline Orchiectomies & $1 \quad(0.9 \%)$ \\
\hline Orchiectomies + antiandrogen & $8(7.7 \%)$ \\
\hline \multicolumn{2}{|l|}{ Outcome } \\
\hline Alive & $50(48.0 \%)$ \\
\hline Cancer-related death & $45(43.2 \%)$ \\
\hline Other cause of death & $9(8.6 \%)$ \\
\hline \multicolumn{2}{|l|}{ Gleason score } \\
\hline 7 & $18(17.3 \%)$ \\
\hline 8 & $31(29.8 \%)$ \\
\hline 9 & $49(47.1 \%)$ \\
\hline 10 & $6(5.8 \%)$ \\
\hline \multicolumn{2}{|l|}{ EOD grade } \\
\hline 1 & $39(37.5 \%)$ \\
\hline 2 & $41(39.4 \%)$ \\
\hline 3 & $15(14.4 \%)$ \\
\hline 4 & $8(7.7 \%)$ \\
\hline $\mathrm{X}$ & $1(0.9 \%)$ \\
\hline \multicolumn{2}{|l|}{ T classification } \\
\hline $\mathrm{T} 1$ & $4(3.8 \%)$ \\
\hline $\mathrm{T} 2$ & $25(24.0 \%)$ \\
\hline $\mathrm{T} 3$ & $24(23.0 \%)$ \\
\hline $\mathrm{T} 4$ & $49(47.1 \%)$ \\
\hline $\mathrm{Tx}$ & $2(1.9 \%)$ \\
\hline \multicolumn{2}{|l|}{$\mathrm{N}$ classification } \\
\hline N0 & $57(54.8 \%)$ \\
\hline N1 & $44(42.3 \%)$ \\
\hline $\mathrm{Nx}$ & $3(2.8 \%)$ \\
\hline
\end{tabular}

\section{Subjects and methods}

Of the 454 patients who were diagnosed with prostate cancer at our hospital between January 1998 and December 2006, 104 with bone metastasis confirmed by bone scintigraphy and with a Karnofsky performance scale of $\geq 70 \%$ were targeted for the present study.

All subjects were treated with endocrine therapy. In all subjects, the prostate-specific antigen (PSA) level was confirmed to have decreased to $\leq 4 \mathrm{ng} / \mathrm{ml}$ after the initiation of treatment, and none of them received chemotherapy with anticancer drugs after recurrence. The last observation was

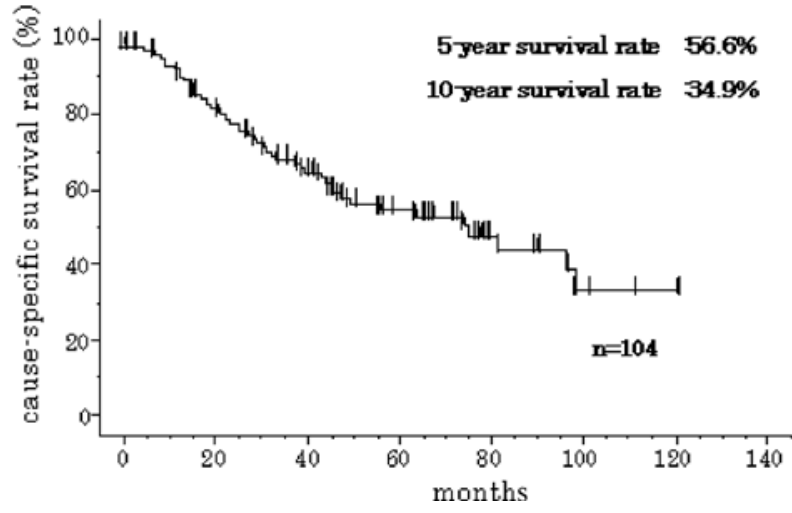

Figure 1. Cause-specific survival curve.

performed on May 31, 2009. The baseline characteristics of the subjects are presented in Table I. The prostate-specific antigen level was measured using a Tandem-R PSA kit (Hybritech, San Diego, CA, USA). The day of determination of the stage was defined as the first day of observation. Histopathological grading was performed using the Gleason score (GS) (8), and the clinical stage was determined based on the International Union Against Cancer (UICC) classification (9). Metastatic spread to bone was assessed by bone scintigraphy and classified according to the extent of disease (EOD) grade (10).

The parameters investigated were $\mathrm{T}$ classification, $\mathrm{N}$ classification, GS, pre-treatment PSA, EOD grade, alkaline phosphatase (ALP), lactate dehydrogenase (LDH), calcium (Ca) and hemoglobin ( $\mathrm{Hb}$ ) levels and platelet (PLT) count.

Survival curves were prepared by the Kaplan-Meier method. To identify predictive factors for the outcome of M1b PC, the subjects who had died of causes other than PC were counted as closed cases in the calculation of the cause-specific survival rate, and the significance of differences was assessed with the log-rank test. For univariate and multivariate analyses, Cox proportional hazard analysis was employed. All statistical analyses were performed with the Statistical Package for Social Sciences (SPSS, Chicago, IL, USA) version 10.0 for Windows. Probability $(\mathrm{P})$ values of $<0.05$ were considered statistically significant.

\section{Results}

In the 104 subjects, the 5-year cause-specific survival rate was $56.6 \%$ and the 10 -year cause-specific survival rate was $34.9 \%$ (Fig. 1).

Each variable was constructed as follows: T classification, T1-3 vs. T4; $\mathrm{N}$ classification, N0 vs. N1; GS, 7 vs. $\geq 8$ (since there was no subject with GS $\leq 6$ ); pre-treatment PSA level, $<192$ vs. $\geq 192$ (since a significant difference in survival rate was observed between these groups); EOD grade, 1+2 vs. $3+4$; ALP, LDH and Ca levels, normal values vs. high values (defined as at least 1.15 times higher than the upper limit of normal); PLT and $\mathrm{Hb}$ levels, normal values vs. low values (defined as not more than 0.85 times lower than the lower limit of the normal).

The log-rank test identified the following factors with statistically significant differences: pre-treatment PSA $\geq 192$, 
Table II. Results of the univariate Cox proportional hazard analysis method and log-rank test.

\begin{tabular}{|c|c|c|c|c|c|}
\hline Factors & $\begin{array}{l}\text { Univariate hazard ratio } \\
\qquad(95 \% \mathrm{Cl})\end{array}$ & P-value & $\begin{array}{l}\text { 5-year cause specific } \\
\text { survival rate }(\%)\end{array}$ & $\begin{array}{l}\text { 10-year cause specific } \\
\text { survival rate }(\%)\end{array}$ & $\begin{array}{l}\text { Log-rank test } \\
\text { P-value }\end{array}$ \\
\hline \multicolumn{6}{|c|}{$\begin{array}{l}\text { Pre-treatment PSA } \\
\text { level }(\mathrm{ng} / \mathrm{ml})\end{array}$} \\
\hline$<192$ & 1 & & 70.1 & 42.8 & \\
\hline$\geq 192$ & $1.98(1.064-3.685)$ & 0.0311 & 45.8 & - & 0.0278 \\
\hline \multicolumn{6}{|l|}{ T stage } \\
\hline $\mathrm{T} 1-3$ & 1 & & 60.5 & 43.0 & \\
\hline $\mathrm{T} 4$ & $1.285(0.706-2.338)$ & 0.4123 & 54.4 & - & 0.3374 \\
\hline \multicolumn{6}{|l|}{ N stage } \\
\hline NO & 1 & & 67.1 & 50.6 & \\
\hline N1 & $2.206(1.207-4.034)$ & 0.0102 & 41.3 & - & 0.0083 \\
\hline \multicolumn{6}{|c|}{ Gleason score } \\
\hline 7 & 1 & & 83.6 & 83.6 & \\
\hline$\geq 8$ & $5.612(1.358-23.194)$ & 0.0172 & 51.2 & 27.1 & 0.0071 \\
\hline \multicolumn{6}{|l|}{ EOD } \\
\hline $1+2$ & 1 & & 60.8 & 39.3 & \\
\hline $3+4$ & $1.978(1.006-3.889)$ & 0.0479 & 37.3 & - & 0.0433 \\
\hline \multicolumn{6}{|l|}{ LDH } \\
\hline Normal & 1 & & 69.3 & 46.9 & \\
\hline High & 3.307 (1.835-5.959) & $<0.0001$ & 29.6 & 14.8 & $<0.0001$ \\
\hline \multicolumn{6}{|l|}{ ALP } \\
\hline Normal & 1 & & 69.6 & 65.9 & \\
\hline High & $2.903(1.559-5.405)$ & 0.0008 & 41.7 & 13.7 & 0.0004 \\
\hline \multicolumn{6}{|l|}{$\mathrm{Hb}$} \\
\hline Normal & 1 & & 72.8 & 50.4 & \\
\hline Low & $2.203(1.168-4.155)$ & 0.0147 & 43.4 & - & 0.0122 \\
\hline \multicolumn{6}{|l|}{ PLT } \\
\hline Normal & 1 & & 57.4 & 38.9 & \\
\hline Low & $1.027(0.519-2.033)$ & 0.9392 & 52.2 & 27.9 & 0.9391 \\
\hline \multicolumn{6}{|l|}{$\mathrm{Ca}$} \\
\hline Normal & 1 & & 57.5 & 38.1 & \\
\hline High & $1.414(0.595-3.358)$ & 0.4328 & 51.1 & - & 0.4293 \\
\hline
\end{tabular}

CI, confidence interval; PSA, prostate-specific antigen; EOD, extent of disease; LDH, lactate dehydrogenase; ALP, alkaline phosphatase; Hb, hemoglobin; PLT, platelet; Ca, calcium.

$\mathrm{N} 1, \mathrm{GS} \geq 8$, EOD grade 3+4, high LDH, high ALP and low Hb. Univariate analysis identified the same factors with statistically significant differences. The hazard ratio was the highest at 5.612 for GS $\geq 8$ (Table II). Multivariate Cox proportional hazard analysis was performed on the factors identified with significant differences by univariate analysis, and determined the factors GS $\geq 8$ and high LDH with statistically significant differences with a hazard ratio of 4.967 and 2.728 , respectively ( $\mathrm{P}=0.029$ and 0.004 , respectively) (Table III). The 5-year cause-specific survival rate was 83.6 and $51.2 \%$, respectively, in subjects with GS 7 and GS $\geq 8$ (Fig. 2), while it was 69.3 and $29.6 \%$, respectively, in subjects with normal and high LDH ( $\mathrm{P}=0.0071$ and $<0.0001$, respectively) (Fig. 3). When subjects with $\mathrm{GS} \geq 8$ and high $\mathrm{LDH}$ were classified as the high-risk group, the 5-year cause-specific survival rate was

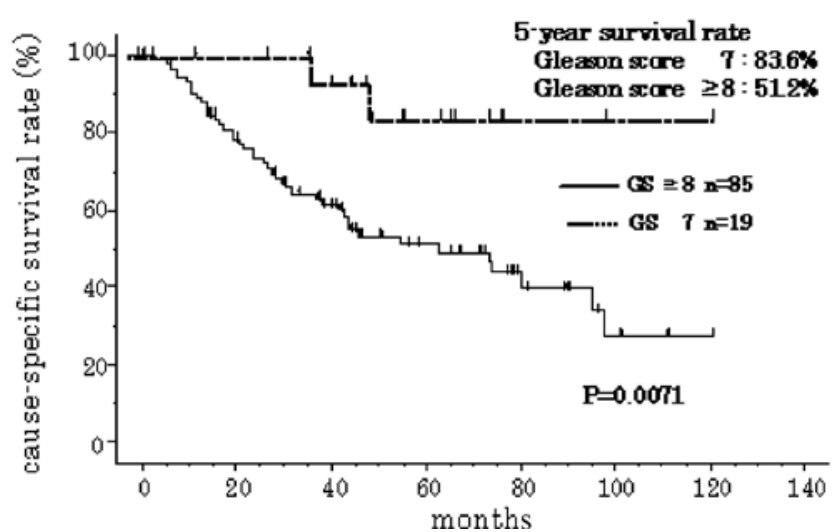

Figure 2. Cause-specific survival curves for Gleason score 7 and $\geq 8$. 
Table III. Results of the multivariate Cox proportional hazard analysis method.

\begin{tabular}{lcr}
\hline Factors & Hazard ratio (95\% CI) & P-value \\
\hline PSA (<192 vs. $\geq 192$ ng/ml) & $1.315(0.658-2.628)$ & 0.438 \\
N classification (N0 vs. N1) & $1.489(0.786-2.821)$ & 0.223 \\
Gleason score (7 vs. $\geq 8)$ & $4.967(1.174-21.01)$ & 0.029 \\
EOD (1+2 vs. 3+4) & $1.232(0.539-2.814)$ & 0.620 \\
LDH (normal vs. high) & $2.728(1.366-5.449)$ & 0.004 \\
ALP (normal vs. high) & $1.829(0.881-3.798)$ & 0.105 \\
Hb (normal vs. low) & $1.037(0.491-2.192)$ & 0.924
\end{tabular}

CI, confidence interval; PSA, prostate-specific antigen; EOD, extent of disease; LDH, lactate dehydrogenase; ALP, alkaline phosphatase; Hb, hemoglobin.

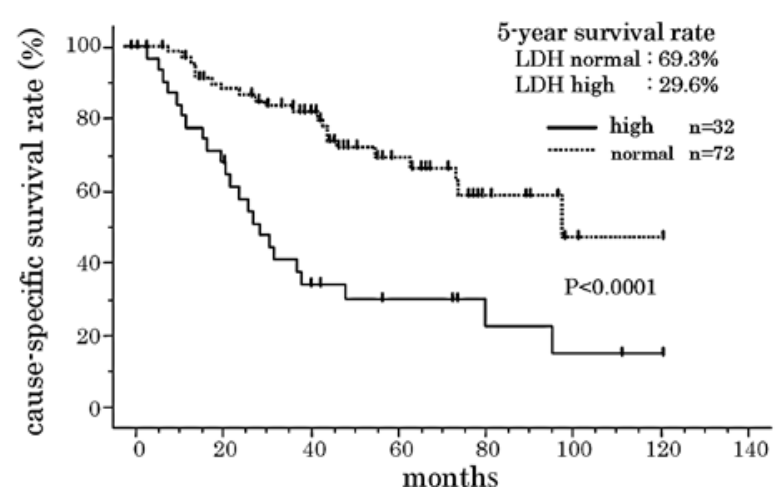

Figure 3. Cause-specific survival curves for normal and high LDH.

24.6\%. Outcome was significantly poorer in this group than in the other group, which had a 5 -year cause-specific survival rate of $67.7 \%(\mathrm{P}<0.0001)$ (Fig. 4).

\section{Discussion}

Approximately $80 \%$ of patients with M1b PC respond to endocrine therapy performed as initial treatment. However, the 5 -year survival rate is known to be as low as $30 \%$ in patients with Mlb PC in Japan, since more than half of the patients become resistant to endocrine therapy within several months to several years (11).

Endocrine resistance is considered to be acquired through abnormalities in the androgen receptor as well as a mechanism not mediated by the androgen receptor. Abnormalities in the androgen receptor include i) androgen receptor amplification (which allows a small amount of androgen to react), ii) androgen receptor gene mutations, iii) abnormalities in coactivators which potentiate the transcriptional activity of the androgen receptor, and iv) androgen receptor activation caused by abnormal production of growth factors or cytokines. We previously reported that HER-2 overexpression in prostate biopsy specimens is an important predictive factor for the acquisition of resistance to endocrine therapy and outcome (12). On the other hand, mechanisms not mediated by the androgen receptor include i) evasion of apoptosis caused by abnormalities in apoptosis-related genes and ii) the

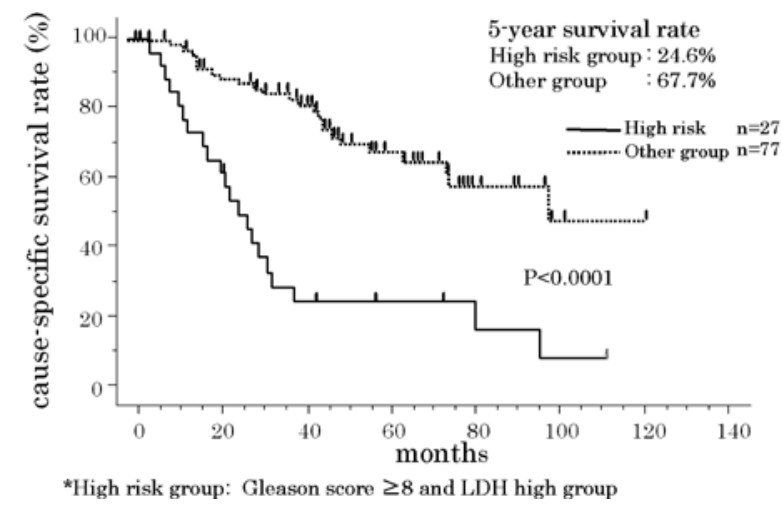

Figure 4. Cause-specific survival curves high risk and other groups. appearance and proliferation of neuroendocrine cells. We also previously reported that neuroendocrine cell differentiation in prostate biopsy specimens is involved in the acquisition of resistance to endocrine therapy (13). Debes and Tindall (7) suggested that these abnormalities do not occur independently, but are involved in the acquisition of endocrine resistance in a complicated manner, but this hypothesis has not yet been verified.

In the present study, the 5-year cause-specific survival rate was $56.6 \%$ and the 10 -year cause-specific survival rate was $34.9 \%$. These favorable results may be attributable to the short mean observation period of 47 months. Some patients with M1b survive for a long time and, thus, it is sometimes difficult to accurately predict the outcome. With regard to predictive factors for the outcome of M1b PC, some studies recently identified: performance scale, GS, response to endocrine therapy, anemia and levels of serum albumin, LDH, ALP and PSA $(14,15)$, while another study showed that EOD grade and interleukin-6 were good predictive factors (16). Still, another study reported that serum cholesterol and interleukin-6 levels are involved in cachexia (17). Thus, no consensus has been reached. In the present study, log-rank test and univariate analysis identified the factors: pre-treatment PSA $\geq 192$, N1, GS $\geq 8$, EOD grade $3+4$, high LDH, high ALP and low $\mathrm{Hb}$ with statistically significant differences.

The presence or absence of lymph node metastasis and GS are involved in the outcome of PC (18-20) and are 
widely known to be clinically important indicators. During the present study, no patient with bone metastasis had GS $\leq 6$. This finding suggests that active surveillance as recommended by Parker (21) and Dall'Era et al (22) is indicated for patients with GS $\leq 6$. During the present study, multivariate Cox proportional hazard analysis identified the factors GS $\geq 8$ and high LDH with significant differences, and more than half of such patients died within 2 years. Such patients have a very poor outcome and should be classified as the high-risk group. The present study targeted patients with a Karnofsky performance score of $70 \%$ or more who could be treated on an outpatient basis, although hospital visits were restricted due to pain, but patients could eat well and take care of themselves. This may have allowed more accurate identification of prognostic factors for M1b PC.

$\mathrm{LDH}$ is an intracellular enzyme widely distributed throughout the tissues of the body. The serum LDH level increases when any tissue is injured and LDH is released into the blood. It is generally measured for screening during initial treatment, and the fractionation of isozymes is useful for determining the injured organ. The serum LDH level is known to become abnormally high in the presence of diseases including acute myocardial infarction, acute hepatitis, leukemia and malignant lymphoma. The serum LDH level is known to become abnormally high in the presence of testicular tumors and is used as an indicator of therapeutic effect. However, only limited types of malignant tumors are associated with high values in the early stage. Therefore, the serum LDH level is generally used as a predictive factor of outcome or an indicator of therapeutic effect or worsening of symptoms. Few patients with M1b PC have increased LDH in the early stage. Some studies showed that serum LDH level is a predictive factor for PC with resistance to endocrine therapy $(23,24)$, while other studies reported the opposite $(15,16)$. Thus, no consensus has been reached. In the present study, however, patients with high LDH had a very poor outcome since, in patients with high LDH, cancer cells have great proliferative capacity and thus a shorter cell cycle which results in increased necrotic cells, and also because cancer cells potentiate the destruction of normal tissue at sites of metastasis. Therefore, the LDH level may be employed as an indicator of tissue destruction in patients with M1b PC.

Patients with M1b PC with GS $\geq 8$ and high pre-treatment LDH may be effectively treated by endocrine therapy combined with docetaxel as reported by Tannock et al (25) and Petrylak et al (26), but therapy with the latter requires further study.

In conclusion, the present study revealed that patients with M1b PC with GS $\geq 8$ and high LDH had a very poor outcome and thus should be treated as a high-risk group requiring close follow-up.

\section{References}

1. Bray F, Sankila R, Ferlay J and Parkin DM: Estimates of cancer incidence and mortality in Europe in 1995. Eur J Cancer 38: 99-166, 2002.

2. Black RJ, Bray F, Ferlay J and Parkin DM: Cancer incidence and mortality in the European Union: cancer registry data and estimates of national incidence for 1990. Eur J Cancer 33 1075-1107, 1997.
3. Parkin DM, Pisani P and Ferlay J: Global cancer statistics. CA Cancer J Clin 49: 33-64, 1999.

4. Hinotsu S: An international comparison of epidemiologic factors of prostate cancer. Nippon Rinsho 65: 171-177, 2007.

5. Schröder FH, Hugosson J, Roobol MJ, et al: Screening and prostate-cancer mortality in a randomized European study. N Engl J Med 360: 1320-1328, 2009.

6. Ito K, Kubota Y, Yamamoto $\mathrm{T}$, et al: The change of mass screening system for prostate cancer in Gunma Prefecture: present state, and problems for 18 years. Jpn J Urol Surg 13: 997-1001, 2000.

7. Debes JD and Tindall DJ: Mechanisms of androgen-refractory prostate cancer. N Engl J Med 351: 1488-1490, 2004.

8. Epstein JI, Allsbrook WC Jr, Amin MB and Egevad LL: The 2005 International Society of Urological Pathology (ISUP) consensus conference on Gleason grading of prostatic carcinoma. Am J Surg Pathol 29: 1228-1242, 2005.

9. Sobin LH and Wittekind Ch: UICC TNM Classification of Malignant Tumors. 6th edition. Wiley-Liss Inc., New York, pp184-187, 2002.

10. Soloway MS, Hardeman SW, Hickey D, Raymond J, Todd B, Soloway S and Moinuddin M: Stratification of patients with metastatic prostate cancer based on extent of disease on initial bone scan. Cancer 61: 195-202, 1988.

11. Kumamoto Y, Tsukamoto T, Umehara T, et al: Clinical studies on endocrine therapy for prostatic carcinoma (2): prognosis of patients with prostatic carcinoma given endocrine therapy, and analyses on causes of death and side effects of endocrine therapy. Hinyokika Kiyo 36: 285-293, 1990.

12. Nishio Y, Yamada Y, Kokubo H, et al: Prognostic significance of immunohistochemical expression of the HER-2/neu oncoprotein in bone metastatic prostate cancer. Urology 68: 110-115, 2006.

13. Kokubo H, Yamada Y, Nishio Y, et al: Immunohistochemical study of chromogranin A in stage D2 prostate cancer. Urology 66: 135-140, 2005.

14. Smaletz O, Scher HI, Small EJ, et al: Nomogram for overall survival of patients with progressive metastatic prostate cancer after castration. J Clin Oncol 20: 3972-3982, 2002.

15. Halabi S, Small EJ, Hayes DF, Vogelzang NJ and Kantoff PW: Prognostic significance of reverse transcriptase polymerase chain reaction for prostate-specific antigen in metastatic prostate cancer: a nested study within CALGB 9583. J Clin Oncol 21: 490-495, 2003

16. Nakashima J, Tachibana M, Horiguchi Y, Oya M, Ohgashi T, Asakura $\mathrm{H}$ and Murai M: Serum interleukin 6 as a prognostic factor in patients with prostate cancer. Clin Cancer Res 6: 2702-2706, 2000.

17. Kuroda K, Nakashima J, Kanao K, et al: Interleukin 6 is associated with cachexia in patients with prostate cancer. Urology 69: 113-117, 2007.

18. Murphy GP and Whitmore WF Jr: A report of the workshops on the current status of the histologic grading of prostate cancer. Cancer 44: 1490-1494, 1979.

19. Bostwick DG: Grading prostate cancer. Am J Clin Pathol 102 (Suppl 1): 38-56, 1994

20. Kambara T, Oyama T, Segawa A, Fukabori Y and Yoshida KI: Prognostic significance of global grading system of Gleason score in patients with prostate cancer with bone metastasis. BJU Int: Nov. 13, 2009 (E-pub ahead of print).

21. Parker C: Active surveillance: towards a new paradigm in the management of early prostate cancer. Lancet Oncol 5: 101-106, 2004.

22. Dall'Era MA, Konety BR, Cowan JE, et al: Active surveillance for the management of prostate cancer in a contemporary cohort. Cancer 112: 2664-2670, 2008.

23. Halabi S, Small EJ, Kantoff PW, et al: Prognostic model for predicting survival in men with hormone-refractory metastatic prostate cancer. J Clin Oncol 21: 1232-1237, 2003.

24. Scher HI, Kelly WM, Zhang ZF, et al: Post-therapy serum prostate-specific antigen level and survival in patients with androgen-independent prostate cancer. J Natl Cancer Inst 91: 244-251, 1999.

25. Tannock IF, de Wit R, Berry WR, et al: Docetaxel plus prednisone or mitoxantrone plus prednisone for advanced prostate cancer. N Engl J Med 351: 1502-1512, 2004.

26. Petrylak DP, Tangen CM, Hussain MH, et al: Docetaxel and estramustine compared with mitoxantrone and prednisone for advanced refractory prostate cancer. N Engl J Med 351: 1513-1520, 2004. 